\title{
Patterns of paediatric end-of-life care: a chart review across different care settings in Switzerland
}

Karin Zimmermann ${ }^{1,2,3^{*}}$, Eva Cignacco ${ }^{1,4}$, Sandra Engberg ${ }^{5}$, Anne-Sylvie Ramelet ${ }^{6,7}$, Nicolas von der Weid ${ }^{8}$, Katri Eskola ${ }^{1,9}$, Eva Bergstraesser ${ }^{3}$, on behalf of the PELICAN Consortium, Marc Ansari, Christoph Aebi, Reta Baer, Maja Beck Popovic, Vera Bernet, Pierluigi Brazzola, Hans Ulrich Bucher, Regula Buder, Sandra Cagnazzo, Barbara Dinten, Anouk Dorsaz, Franz Elmer, Raquel Enriquez, Patricia Fahrni-Nater, Gabi Finkbeiner, Bernhard Frey, Urs Frey, Jeannette Greiner, Ralph-Ingo Hassink, Simone Keller, Oliver Kretschmar, Judith Kroell, Bernard Laubscher, Kurt Leibundgut, Reta Malaer, Andreas Meyer, Christoph Stuessi, Mathias Nelle, Thomas Neuhaus, Felix Niggli, Geneviève Perrenoud, Jean-Pierre Pfammatter, Barbara Plecko, Debora Rupf, Felix Sennhauser, Caroline Stade, Maja Steinlin, Lilian Stoffel, Karin Thomas, Christian Vonarburg, Rodo von Vigier, Bendicht Wagner, Judith Wieland and Birgit Wernz

\begin{abstract}
Background: Paediatric end-of-life care is challenging and requires a high level of professional expertise. It is important that healthcare teams have a thorough understanding of paediatric subspecialties and related knowledge of diseasespecific aspects of paediatric end-of-life care. The aim of this study was to comprehensively describe, explore and compare current practices in paediatric end-of-life care in four distinct diagnostic groups across healthcare settings including all relevant levels of healthcare providers in Switzerland.
\end{abstract}

Methods: In this nationwide retrospective chart review study, data from paediatric patients who died in the years 2011 or 2012 due to a cardiac, neurological or oncological condition, or during the neonatal period were collected in 13 hospitals, two long-term institutions and 10 community-based healthcare service providers throughout Switzerland.

Results: Ninety-three (62\%) of the 149 reviewed patients died in intensive care units, 78 (84\%) of them following withdrawal of life-sustaining treatment. Reliance on invasive medical interventions was prevalent, and the use of medication was high, with a median count of 12 different drugs during the last week of life. Patients experienced an average number of 6.42 symptoms. The prevalence of various types of symptoms differed significantly among the four diagnostic groups. Overall, our study patients stayed in the hospital for a median of six days during their last four weeks of life. Seventy-two patients (48\%) stayed at home for at least one day and only half of those received community-based healthcare.

(Continued on next page)

\footnotetext{
*Correspondence: karin.zimmermann@unibas.ch

'Department Public Health (DPH), Nursing Science, University of Basel,

Bernoullistrasse 28, 4056 Basel, Switzerland

2Paediatric Palliative Care, University Children's Hospital Zurich, Children's

Research Center CRC, Steinwiesstrasse 75, 8032 Zurich, Switzerland

Full list of author information is available at the end of the article
}

(c) The Author(s). 2018 Open Access This article is distributed under the terms of the Creative Commons Attribution 4.0 International License (http://creativecommons.org/licenses/by/4.0/), which permits unrestricted use, distribution, and reproduction in any medium, provided you give appropriate credit to the original author(s) and the source, provide a link to the Creative Commons license, and indicate if changes were made. The Creative Commons Public Domain Dedication waiver (http://creativecommons.org/publicdomain/zero/1.0/) applies to the data made available in this article, unless otherwise stated. 
(Continued from previous page)

Conclusions: The study provides a wide-ranging overview of current end-of-life care practices in a real-life setting of different healthcare providers. The inclusion of patients with all major diagnoses leading to disease- and prematurityrelated childhood deaths, as well as comparisons across the diagnostic groups, provides additional insight and understanding for healthcare professionals. The provision of specialised palliative and end-of-life care services in Switzerland, including the capacity of community healthcare services, need to be expanded to meet the specific needs of seriously ill children and their families.

Keywords: End-of-life care, Terminal care, Paediatrics, Neonatology, Child, Practice patterns, Retrospective studies

\section{Background}

Despite continued advancements in medical care and improved (expected) survival, infant and childhood deaths due to complex chronic conditions (CCC) or prematurity are inevitable [1]. Deaths during the first year of life constitute approximately $50 \%$ of disease-related infant and childhood deaths in developed countries, the causes of which include perinatal complications, prematurity, or congenital anomalies [2, 3]. Beyond the age of one year, the three most common life-limiting CCCs are neurological/neuromuscular and cardiovascular conditions (including genetic disorders), and malignancies [4, 5]. The majority of disease- and prematurity-related deaths occur in hospitals, [6, 7], and for children dying at home, hospital use in their terminal stage is high [1, 4]. Symptom burden and reliance on medical technology has been reported to be considerable $[3,8]$. Circumstances and characteristics of deaths, however, are known to vary by age and medical conditions $[1,4]$.

Paediatric palliative care (PPC) emerged as a medical subspecialty aimed at meeting the specific needs of seriously ill children and their families. According to the World Health Organization (WHO) "palliative care is an approach that improves the quality of life of patients and their families facing the problem associated with lifethreatening illness, through the prevention and relief of suffering by means of early identification and impeccable assessment and treatment of pain and other problems, physical, psychosocial and spiritual" [9]. More specifically and as part of palliative care, the term end-of-life (EOL) care refers to care when death is imminent [10]. Meeting the needs of affected children and their families requires a wide-ranging and integrative approach from a compassionate and skilled multidisciplinary team [11]. PPC and EOL care should be provided in all settings where it is required [12]; although, specialised PPC teams are mostly hospital based [13]. A thorough understanding of paediatric subspecialties and related knowledge of disease-specific aspects of paediatric EOL are needed. This understanding should go beyond the horizon of a single hospital and take into account the heterogeneous settings where care can be provided (tertiary settings, general hospitals, paediatric primary care and in the community). There is not much evidence on which to base best practice, and most existing studies focus on specific diagnostic groups or specific care settings $[1,14,15]$. It was therefore the aim of this national study to comprehensively describe, explore and compare current practices in paediatric EOL care in four distinct diagnostic groups (cardiology, neonatology, neurology and oncology) across healthcare settings including all relevant levels of healthcare providers in Switzerland.

\section{Methods \\ Study design}

This retrospective chart review was part of PELICAN (Paediatric End-of-LIfe-CAre Needs in Switzerland), a nationwide study "to provide comprehensive information and to understand the current practice of EOL care (i.e. in this study and similar to other studies, the last 4 weeks of life prior to death [16]) in paediatric settings in Switzerland (hospital and community care) and to explore and describe parental perspectives and the perspectives of the healthcare professionals involved" [17]. Human Research Ethics Committees from the 11 Swiss cantons in which the study took place approved the PELICAN study. Parents who had lost a child due to a cardiac, neurological or oncological condition or during the neonatal period (independent of the underlying condition) in the years 2011 and 2012 were invited to participate. Neonates < $24 \mathrm{~h}$ of life and patients $>18$ years were excluded. Information on how, where and when recruitment took place is described in detail elsewhere [18].

\section{Setting and data collection}

Data from all eligible patients, whose parents had consented to the review of their child's medical chart, were collected in 13 hospitals, 2 institutions and 10 community-based healthcare service providers throughout Switzerland. Among the 13 hospitals, there were 5 tertiary paediatric centres, 4 dedicated children's hospitals, 3 general hospitals with paediatric units and 1 tertiary care centre with a neonatal intensive care unit. A multiprofessional PPC team was available in two tertiary paediatric centres and one dedicated children's hospital; no paediatric hospices exist in Switzerland. 
Data collection was conducted mainly by the first author, who also developed the coding manual and all case report forms as well as instructing and supervising five assistants, who supported data collection [19]. The coding manual was developed within the PELICAN study group [17] and pilot tested with 10 children who were treated in 5 different hospitals and died in the year 2010. In accordance with this study's definition of EOL care as care during the last four weeks of life, data collection was restricted to the 28 days prior to the child's death. All extracted data was entered into secuTrial $^{\circ}$, a browser-based electronic data capture system (InterActive Systems, Berlin, Germany). During the first two months of data collection, $5 \%$ of the medical records reviewed by one of the five assistants were randomly selected and audited by $\mathrm{KZ}$ by performing a dual review. Any data entry discrepancies were checked for its nature of assessment error. No systemic data entry errors were detected. There were very few data entry discrepancies and those that occurred were almost always related to mixed documentation quality in the medical records that left room for interpretation, e.g., change of do-not-resuscitate (DNR) order. Emerging questions around those inconsistencies were continuously discussed among data collectors. Variable instructions in the manual were revised as needed to ensure the quality of ongoing data extraction and reduce the likelihood of inter-rater discrepancies [19].

\section{Variables}

The following data were collected for this study: (1) demographics (age, gender); (2) diagnostic information (the underlying diagnosis primarily responsible for the patient's death, gestational age for newborns only, time since diagnosis, and whether the diagnosis was made prenatally); (3) circumstances of death (place of death, occurrence of resuscitation, existence of DNR orders and whether these orders changed during the last four weeks of life, and treatment withdrawal); (4) interventions (at least once during the last four weeks of life, Yes-No: anaesthesia, e.g., surgery, imaging; ventilation; central access device; enteral feeds) and medications (number and types of medications were recorded only for the last two weeks of life to reduce the time burden related to reviewing the medical records); (5) symptoms (presence of various symptoms); (6) hospital and community healthcare utilisation (hospital days and admissions, days spent at home, number of days and hours, and types of care provided by community services). We also assessed whether the treatment approach was documented as palliative care and whether this approach changed during the last four weeks of life.

A diagnostic chapter and code from the International Statistical Classification of Diseases and Related Health
Problems (ICD), 10th Revision, online version 2016 [20] was assigned to each patient, based on the exact diagnostic information extracted from the patient's last medical report. Coding was done by two independent appraisers to establish reliability and any discrepancies were discussed until there was consensus about the diagnosis. All symptoms documented in the patient's chart were recorded during data collection. The ones most frequently reported were grouped into 20 symptoms categories, based on symptoms most frequently reported in the literature $[8,14,21]$. Symptoms that affected similar areas, e.g. spasticity/dystonia for muscular impairments, or agitation/irritability for behavioural problems, were grouped.

\section{Statistical analysis}

Descriptive statistics (measures of central tendency and dispersion, frequencies and percentages) were used to explore and summarize all variables. A binary logistic model with likelihood ratio statistics was utilised for two-tailed comparisons between the diagnostic groups of variables with a binominal response (Yes - No). For count outcome variables, negative binomial regression was utilised to adjust for overdispersion [22]. For variables with a categorical response, equivalence of proportions between diagnostic groups was tested in contingency tables using the Pearson's chi-square test or Fisher's exact test when cell sizes were $<5$. No measures of missing value replacement were pursued. Due to the multiple comparisons performed, we set a conservative $p$-value of $<0.001$ to indicate statistical significance. Statistical analyses were performed using IBM॰ SPSS $\odot$ Statistics 21 for $\mathrm{Mac}^{\circ}$ (IBM Corp, Armonk, NY, USA).

\section{Results}

Of the 307 eligible families, 267 could be contacted and were invited to participate in the PELICAN study. Of those, 147 families (55\%) consented. Two families lost twins resulting in a study sample of 149 neonates, children and adolescents (Table 1). With neonates comprising $38 \%$ of the sample, the median age at death was 0.5 years for the entire sample but substantially higher $(M d n=8.4$, range $=1.7-17.4$ years $)$ for the oncology group. The neonates' median age was 5 days (range $=1$ 26) and substantially lower than age in the other diagnostic groups (Table 1). Seven ICD-10 diagnostic chapters were represented in our four groups' categorisation, with the highest variety found within the neurology group. The median time between diagnosis of the lifelimiting CCC (made after birth) and death for the total sample was one month (interquartile range [IQR], 0 6). Within the four groups, the median time between diagnosis and death was longest for the neurology group $(M d n=6$ months, IQR $=3$ - 29). Diagnoses made 
Table 1 Demographic and diagnostic patient characteristics

\begin{tabular}{|c|c|c|c|c|c|}
\hline Characteristics & $\begin{array}{l}\text { Total } \\
N=149 \\
(100 \%)\end{array}$ & $\begin{array}{l}\text { Cardiology } \\
n=19 \\
(13 \%)\end{array}$ & $\begin{array}{l}\text { Neonatology } \\
n=57 \\
(38 \%)\end{array}$ & $\begin{array}{l}\text { Neurology } \\
n=36 \\
(24 \%)\end{array}$ & $\begin{array}{l}\text { Oncology } \\
n=37 \\
(25 \%)\end{array}$ \\
\hline \multicolumn{6}{|l|}{ Age at death, Mdn (range) } \\
\hline in months & $6(0-209)$ & $6(1-109)$ & $\mathrm{Na}$ & $19(1-207)$ & $101(20-209)$ \\
\hline in years & $0.5(0.0-17.4)$ & $0.5(0.1-9.1)$ & $\mathrm{Na}$ & $1.6(0.1-17.2)$ & $8.4(1.7-17.4)$ \\
\hline \multicolumn{6}{|l|}{ Gender, $n(\%)$} \\
\hline Female & $72(48)$ & $10(53)$ & $32(56)$ & $15(42)$ & $15(40)$ \\
\hline Male & $77(52)$ & $9(47)$ & $25(44)$ & $21(58)$ & $22(60)$ \\
\hline \multicolumn{6}{|l|}{ ICD-10 chapter, description, $n$ (\%) } \\
\hline II Neoplasms & $36(24)$ & $0(0)$ & $0(0)$ & $0(0)$ & $36(97)$ \\
\hline III Blood/immune system & $1(1)$ & $0(0)$ & $0(0)$ & $0(0)$ & $1(3)^{\mathrm{a}}$ \\
\hline IV Endocrine, nutritional, metabolic & $6(4)$ & $0(0)$ & $0(0)$ & $6(16)$ & $0(0)$ \\
\hline VI Nervous system & $21(14)$ & $0(0)$ & $2(4)$ & $19(53)$ & $0(0)$ \\
\hline IX Circulatory system ${ }^{b}$ & $5(3)$ & $4(21)$ & $0(0)$ & $1(3)$ & $0(0)$ \\
\hline $\mathrm{XVI}$ Conditions originating in perinatal period & $45(30)$ & $0(0)$ & $44(77)$ & $1(3)$ & $0(0)$ \\
\hline XVII Congenital, chromosomal & $35(24)$ & $15(79)$ & $11(19)$ & $9(25)$ & $0(0)$ \\
\hline Gestational age (for the neonatology group only) & & & $n=52^{c}$ & & \\
\hline $240 / 7-276 / 7$ & $\mathrm{Na}$ & $\mathrm{Na}$ & $17(33)$ & $\mathrm{Na}$ & $\mathrm{Na}$ \\
\hline $280 / 7-316 / 7$ & $\mathrm{Na}$ & $\mathrm{Na}$ & $8(15)$ & $\mathrm{Na}$ & $\mathrm{Na}$ \\
\hline $320 / 7-366 / 7$ & $\mathrm{Na}$ & $\mathrm{Na}$ & $9(17)$ & $\mathrm{Na}$ & $\mathrm{Na}$ \\
\hline $370 / 7$ - > 42 0/7 & $\mathrm{Na}$ & $\mathrm{Na}$ & $18(35)$ & $\mathrm{Na}$ & $\mathrm{Na}$ \\
\hline \multicolumn{6}{|l|}{ Time since diagnosis $^{\mathrm{d}}$} \\
\hline in days, Mdn (range) & $\mathrm{Na}$ & $\mathrm{Na}$ & $4(1-26)$ & $\mathrm{Na}$ & $\mathrm{Na}$ \\
\hline in months, Mdn (range) & $1(0-205)$ & $7(0-66)$ & $\mathrm{Na}$ & $9(0-205)$ & $4(0-139)$ \\
\hline in years, Mdn (range) & $0(0-17)$ & $0.5(0.5-5.5)$ & $\mathrm{Na}$ & $0.5(0.0-17.0)$ & $0.5(0.0-12.0)$ \\
\hline Diagnosis made prenatally & $n=147^{c}$ & & & $n=34^{c}$ & \\
\hline Yes, $n(\%)$ & $31(21)$ & $11(58)$ & $13(23)$ & $7(21)$ & $0(0)$ \\
\hline
\end{tabular}

Na Not applicable, ICD-10 International Classification of Diseases, 10th Revision

${ }^{\text {a Aplastic anaemia }}$

${ }^{\text {b }}$ Stroke included

'Information was missing for some cases

${ }^{\mathrm{d} C a l c u l a t e d}$ from date of birth, even if diagnosis was suspected prenatally

prenatally, were significantly more frequent in the cardiology group compared to the other groups $(p=<0.001)$ and not present in the oncology group. Information related to gestational age was missing for 5 neonates $(8.8 \%)$ and information related to diagnoses made prenatally for 2 patients $(1.3 \%)$ (Table 1$)$.

\section{Place and circumstances of death}

Ninety-three patients $(62 \%)$ died in an intensive care unit (ICU), with the highest proportion of ICU deaths occurring in the neonatology group (Table 2). Twenty-five patients $(17 \%)$ died at home, with the highest proportion of home deaths occurring in the oncology group. Twenty-six patients (17\%) received cardiopulmonary resuscitation (CPR) within $24 \mathrm{~h}$ before death, despite 15 patients $(17 \%, n=147)$ had a documented DNR order. A DNR order was documented in 91 patients' charts (62\%). Of those, 51 patients $(57 \%)$ had a change of the DNR order within the last four weeks of life. This change occurred most frequently in the neonatology group (Table 2), often within hours before the child's death. For 78 patients (84\%) of the 93 who died in an ICU, death was preceded by a decision to withdraw life-sustaining interventions.

\section{Interventions, medication and symptoms}

Patients underwent several interventions, suffered from a variety of symptoms, and received a considerable amount of medication, as documented in their charts. This information is detailed in Table 3 and Fig. 1. Fifty-one patients $(34 \%)$ received anaesthesia at least once 
Table 2 Place and circumstances of death

\begin{tabular}{|c|c|c|c|c|c|c|}
\hline & $\begin{array}{l}\text { Total } \\
N=149 \\
(100 \%)\end{array}$ & $\begin{array}{l}\text { Cardiology } \\
n=19 \\
(13 \%)\end{array}$ & $\begin{array}{l}\text { Neonatology } \\
n=57 \\
(38 \%)\end{array}$ & $\begin{array}{l}\text { Neurology } \\
n=36 \\
(24 \%)\end{array}$ & $\begin{array}{l}\text { Oncology } \\
n=37 \\
(25 \%)\end{array}$ & $p$-value \\
\hline Place of death, $n(\%)$ & & & & & & $<0.001^{\circ}$ \\
\hline $\mathrm{PICU}$ & $63(42)$ & $13(67)$ & $27(48)$ & $13(36)$ & $10(27)$ & \\
\hline $\mathrm{NICU}$ & $30(20)$ & $0(0)$ & $27(48)$ & $3(8)$ & $0(0)$ & \\
\hline Hospital ward / long-term institution & $26(18)$ & $2(11)$ & $0(0)$ & $13(36)$ & $11(30)$ & \\
\hline Home & $25(17)$ & $2(11)$ & $2(3)$ & $7(20)$ & $14(38)$ & \\
\hline Emergency department / Transport & $5(3)$ & $2(11)$ & $1(1)$ & $0(0)$ & $2(5)$ & \\
\hline \multicolumn{7}{|l|}{$\mathrm{CPR}^{\mathrm{b}}$} \\
\hline Yes, $n(\%)$ & $26(17)$ & $7(37)$ & $6(11)$ & $7(19)$ & $6(16)$ & $0.097^{\circ}$ \\
\hline \multicolumn{7}{|l|}{ DNR order } \\
\hline Yes, $n(\%)$ & $91(62)$ & $11(58)$ & $20(35)$ & $33(92)$ & $27(77)$ & $<0.001$ \\
\hline \multicolumn{7}{|c|}{ DNR order change within the last four weeks of life } \\
\hline Yes, $n(\%)$ & $51(57)$ & $7(64)$ & $18(90)$ & $13(41)$ & $13(48)$ & 0.002 \\
\hline Withdrawal of life-sustaining interventions ${ }^{d}$ & $n=93$ & $n=13$ & $n=54$ & $n=16$ & $n=10$ & \\
\hline Yes, $n(\%)$ & $78(84)$ & $10(77)$ & $49(91)$ & $12(75)$ & $7(70)$ & $0.203^{\circ}$ \\
\hline
\end{tabular}

PICU Paediatric intensive care unit, NICU Neonatal intensive care unit, CPR Cardiopulmonary resuscitation, DNR Do not resuscitate

${ }^{a}$ Across the four groups, based on Fisher's exact test

${ }^{b}$ Within $24 \mathrm{~h}$ before death

${ }^{\mathrm{c}}$ Across the four groups, based on likelihood ratio chi-square

Only applies to patients who died in an intensive care unit

during their last four weeks of life, some patients more than once and for different interventions. The most commonly documented interventions requiring anaesthesia were surgical interventions in 28 patients $(55 \%$ of the 51 patients who received anaesthesia) and diagnostic procedures, e.g. imaging in 27 patients (53\%). The overall median and mean number of medications with orders for standard daily doses and as-needed orders rose from 9 (range $=0-42), 12(S D=9.20)$ respectively during the second-to-last week to 12 (range $=1-46), 14(S D=$ 9.15) respectively during the last week. For 133 patients (89\%) the last treatment approach was documented as palliative. The approach changed from curative to palliative during the last month in 88 patients (59\%), most commonly in the neonatology group and least commonly in the oncology group ( $90 \%$ vs. $32 \%, p=<0.001$ ). Information was missing for six variables related to interventions and medication and ranged between $0.7 \%$ and $2.7 \%$ (Table 3 ).

Pain was the most frequently documented symptom, and occurred in 110 patients $(78 \%, N=141)$, with no significant differences between the diagnostic groups. One hundred and forty patients $(95 \%, N=148)$ received some pain medication, most commonly opioids (93\%), followed by paracetamol (67\%). Other common symptoms included breathing problems $(n=107,72 \%)$, followed by behavioural problems such as agitation or irritability $(n=89,60 \%)$. Some symptoms, such as respiratory secretion, fever, nausea/vomiting, coughing, sweating, fatigue, drowsiness, anxiety (including worry and sadness), and poor appetite, differed significantly $(p=<0.001)$ between the diagnostic groups (Figure 1). Overall, an average of $6.42(S D=3.14)$ symptoms were recorded per patient. Significantly fewer symptoms were reported in neonates $(M=4.39, S D=2.15)$ compared to all other groups $(p=<0.001)$.

\section{Hospital and community healthcare utilisation}

Overall, our study patients stayed in the hospital for a median of six days $(I Q R=2-19)$ during their last four weeks of life, with the highest number of hospital days for patients in the cardiology group (Table 4). Nineteen patients (13\%) had no hospital days: 11 of them (58\%) from the oncology group, 5 (26\%) from the neurology group, 3 (16\%) from the cardiology group, and none from the neonatology group. Among the 130 patients who had at least one hospital day, 62 patients (48\%) had one hospital admission, 10 patients (8\%), and 2 patients (1\%) had 3 admissions during the last four weeks of life. Fifty-six patients (43\%) had zero hospital admissions, meaning that those patients were hospitalised at the beginning of data collection and remained there until their death or discharge. Of the 57 patients in the neonatology group, 23 patients (40\%) were born in a hospital with no ICU and had to be transferred to a referral tertiary hospital with an ICU. Patients from the other diagnostic groups were most commonly admitted from home (Table 4). 
Table 3 Interventions and medications during the last four weeks of life

\begin{tabular}{|c|c|c|c|c|c|c|}
\hline & $\begin{array}{l}\text { Total } \\
N=149 \\
(100 \%)\end{array}$ & $\begin{array}{l}\text { Cardiology } \\
n=19 \\
(13 \%)\end{array}$ & $\begin{array}{l}\text { Neonatology } \\
n=57 \\
(38 \%)\end{array}$ & $\begin{array}{l}\text { Neurology } \\
n=36 \\
(24 \%)\end{array}$ & $\begin{array}{l}\text { Oncology } \\
n=37 \\
(25 \%)\end{array}$ & $p$-value \\
\hline Interventions requiring anaesthesia & $n=148^{\mathrm{a}}$ & & & $n=35^{\mathrm{a}}$ & & \\
\hline Yes, n (\%) & $51(34)$ & $11(58)$ & $21(37)$ & $6(17)$ & $13(35)$ & $0.021^{b}$ \\
\hline \multicolumn{7}{|l|}{ Mechanical ventilation } \\
\hline Yes, $n(\%)$ & $94(63)$ & $14(74)$ & $55(97)$ & $15(42)$ & $10(27)$ & $<0.001^{\mathrm{b}}$ \\
\hline \multicolumn{7}{|l|}{ ECMO } \\
\hline Yes, $n(\%)$ & $7(5)$ & $4(21)$ & $3(5)$ & $0(0)$ & $0(0)$ & $<0.001^{\mathrm{b}}$ \\
\hline Presence of CAD & $n=148^{\mathrm{a}}$ & & & & $n=36^{\mathrm{a}}$ & \\
\hline Yes, n (\%) & $106(72)$ & $14(74)$ & $55(97)$ & $12(33)$ & $25(69)$ & $<0.001^{\mathrm{b}}$ \\
\hline Enteral feeds via nasogastric or gastrostomy tube & $n=148^{a}$ & & & $n=35^{\mathrm{a}}$ & & \\
\hline Yes, $n(\%)$ & $114(77)$ & $17(90)$ & $51(90)$ & $33(94)$ & $13(35)$ & $<0.001^{b}$ \\
\hline Medication count in the last week of life ${ }^{c}$ & $n=146^{\mathrm{a}}$ & & & $n=35^{\mathrm{a}}$ & $n=35^{\mathrm{a}}$ & \\
\hline Mdn, (range) & $12(1-46)$ & $19(3-45)$ & $12(1-34)$ & $10(3-39)$ & $13(4-46)$ & $0.006^{b}$ \\
\hline Mean, (SD) & $14(9.15)$ & $21(11.73)$ & $12(7.02)$ & $13(8.82)$ & 15 (9.69) & \\
\hline Pain medication & $n=148^{\mathrm{a}}$ & & & $n=35^{\mathrm{a}}$ & & \\
\hline Yes, n (\%) & $140(95)$ & $18(95)$ & $54(95)$ & $33(94)$ & $35(95)$ & $1.000^{b}$ \\
\hline Anxiolytic medication & $n=145^{a}$ & & & $n=35^{\mathrm{a}}$ & $n=34^{\mathrm{a}}$ & \\
\hline Yes, $n(\%)$ & $84(58)$ & $14(74)$ & $27(47)$ & $18(51)$ & $25(74)$ & $0.032^{b}$ \\
\hline Antiemetic medication & $n=146^{a}$ & & & $n=35^{\mathrm{a}}$ & $n=35^{\mathrm{a}}$ & \\
\hline Yes, n (\%) & $25(17)$ & $2(11)$ & $0(0)$ & $0(0)$ & $23(66)$ & $<0.001^{\mathrm{b}}$ \\
\hline
\end{tabular}

ECMO Extracorporeal membrane oxygenation, $C A D$ Central access device, either venous or arterial

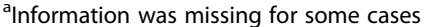

${ }^{\mathrm{b}}$ Across the four groups, based on likelihood ratio chi-square

Includes both standing daily dosages and as-needed orders

Seventy-two patients (48\%) stayed at home for at least one day, with patients from the oncology group having the highest number of home days $(M d n=24, I Q R=4$ 28 ), followed by patients from the neurology group ( $M d n$ $=21, I Q R=4-26)$. Of the 72 patients who stayed at home, $36(50 \%)$ received professional care from a communitybased service. The provision of education and support to empower the family was the most commonly provided service, as documented by the care provider, and patients from the neurology group received more care hours than patients from the other groups (Table 4).

\section{Discussion}

There are several principal findings in this nationwide study examining patterns of care at EOL in four distinct diagnostic groups: patients had a variety of primary diagnoses, covering seven different ICD-10 diagnostic chapters; $62 \%$ of all patients died in ICUs, with $84 \%$ of them following a decision to withdraw life-sustaining treatment; reliance on invasive medical interventions was prevalent and patients were exposed to multiple medications; patients experienced many symptoms with an average of six symptoms per patient; finally, communitybased health care services were involved in only half of the cases of the 72 patients (48\%) of patients who spent time at home during their last four weeks of life.

\section{Strengths and limitations}

The study provides a wide-ranging overview of current EOL care practices in a heterogeneous real-life setting of hospitals, long-term institutions and community healthcare organisations. The inclusion of patients with all major diagnoses leading to disease- and prematurityrelated infant and childhood deaths, as well as comparisons across the diagnostic groups, provides additional insight and understanding for healthcare professionals. Previous studies in this field have frequently been limited to the hospital setting $[1,3]$ or to a specific diagnostic group [8, 14, 15]. Our study is limited by its cross-sectional, primarily descriptive design incorporating a retrospective chart review. This approach does not allow conclusions to be drawn about care quality and quality of life at the EOL. Generalisability is further limited by the way that EOL care is often delivered in Switzerland. Specialised PC/EOL care was offered in only 3 of the 13 hospitals where data were collected, and no children's hospices exist in Switzerland. The study's definition of EOL care as the last four weeks of life is 


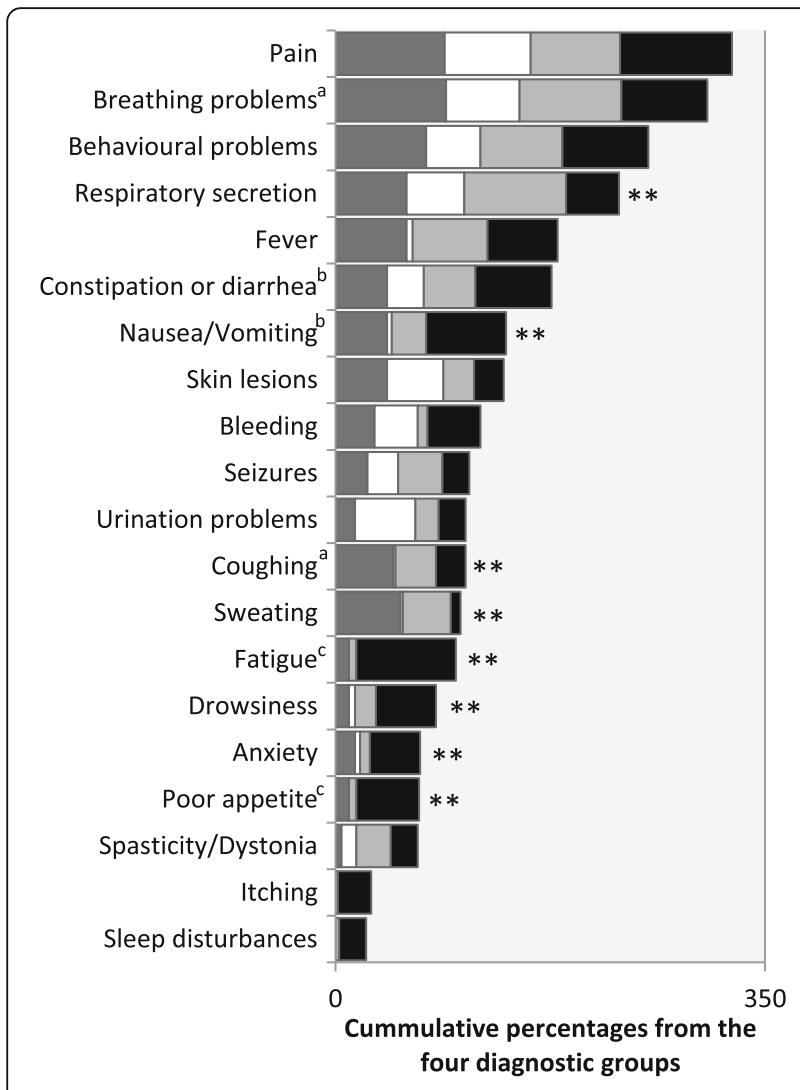

- Cardiology $\square$ Neonatology $\square$ Neurology $\square$ Oncology

Fig. 1 Symptom prevalence and comparison between the four diagnostic groups. ${ }^{* *}=p$-value $<0.001$ based on a negative binomial regression model. ${ }^{\mathrm{a} A d j u s t e d ~ f o r ~ m e c h a n i c a l ~ v e n t i l a t i o n . ~}{ }^{\mathrm{b}}$ Adjusted for enteral feeds. ${ }^{c}$ Neonatology group excluded due to $0 \%$ of symptom presence

somehow artificial, yet was justified by the literature, experts' opinion and feasibility constraints. The study, therefore, provides insight in paediatric EOL care in a limited time frame, not necessarily covering all aspects of EOL care across a broader time period. Known reliability issues related to chart reviews were kept to a minimum by utilising established and appropriate measures, resulting in few discrepancies in the data collected. However, the mixed quality of documentation among healthcare personnel, resulting in incomplete or missing data independent of data collection quality still limits the study's reliability [19]. The comparisons between the four major diagnostic groups highlight elements that warrant discussion.

\section{Medication and symptoms}

Medication counts in our study were high, with an overall mean of 14 drugs or as-needed medication orders during the last week of life. This number is higher than the reported average of 9 drugs in a study involving 515 paediatric patients with a similar diagnostic profile receiving PPC
[3]. A similar average number of $13.9(S D=8.9)$ of medications used in the last week of life was reported in a study of 30 children dying in an Australian hospital in 2001. Two thirds of the 30 children died in the ICU, which might have influenced the high numbers found in this study [23]. We found that the medication count increased from the second-to-last week to the last week of life. Thus, it seems that the intensity of medical treatment increases as the child nears death, a phase which is accompanied by a greater need for pharmacological interventions, especially for relieving pain, based on our clinical experience. The high number of medications in the cardiology group was often due to the frequent need for CPR and a high prevalence of surgical interventions, which are also described in other studies with cardiology patients $[15,21]$. Although not perfectly comparable, symptom type and prevalence differed from the aforementioned study of 515 patients receiving PPC, in which pain was only the sixth most frequent symptom extracted from patients' charts [3]. However, pain has been reported to be the most frequent symptom in other studies with various paediatric cohorts in PC or EOL care $[8,14]$. Our study adds to existing knowledge by demonstrating that symptom prevalence is dependent on the underlying $\mathrm{CCC}$ and that it can differ considerably.

\section{Hospital and community healthcare utilisation}

Most patients $(n=130)$ stayed at least one day in hospital during their last four weeks of life. Of those, 62 patients (48\%) had at least one hospital admission and 10 patients (8\%) had more than one admission. This is a lower percentage than reported in a recent North American study about trends in high-intensity EOL care among children with cancer [24]. In this population-based study with a cohort of 815 children diagnosed with cancer who died between 2000 and 2012, 143 patients (17.6\%) of the patients had more than one hospital admission within 30 days of death. Compared with our oncology sub-group $(n=37)$, twenty-six patients stayed at least one day in hospital and 3 (11\%) of them had more than one admission during their last four weeks of life.

Slightly less than $50 \%$ of our study's patients were at home at some point during their last four weeks of life. Naturally, this was the case for very few neonates. In light of the probably growing rate of prenatal diagnosis of a life-limiting CCC, early initiation of PPC may allow better planning and implementation of specialised care services at home [25]. Perinatal palliative care is an even younger specialty than PPC [25] and was not integrated in the three PPC programmes in Switzerland. A recent survey about the provision of services showed that perinatal palliative care programmes in the US were based in academic medical centres, regional and local hospitals, or community based hospitals [26]. Back in 
Table 4 Hospital and community healthcare utilisation during the last four weeks of life

\begin{tabular}{|c|c|c|c|c|c|c|}
\hline & $\begin{array}{l}\text { Total } \\
N=149 \\
(100 \%)\end{array}$ & $\begin{array}{l}\text { Cardiology } \\
n=19 \\
(13 \%)\end{array}$ & $\begin{array}{l}\text { Neonatology } \\
n=57 \\
(38 \%)\end{array}$ & $\begin{array}{l}\text { Neurology } \\
n=36 \\
(24 \%)\end{array}$ & $\begin{array}{l}\text { Oncology } \\
n=37 \\
(25 \%)\end{array}$ & $p$-value \\
\hline Hospital days, Mdn (range) & $6(0-28)$ & $20(0-28)$ & $5(1-26)$ & $7(0-28)$ & $4(0-28)$ & $0.035^{\mathrm{a}}$ \\
\hline Care setting before hospital admission ${ }^{\mathrm{b}}, n(\%)$ & $n=88$ & $n=17$ & $n=23$ & $n=26$ & $n=22$ & \\
\hline Home & $37(42)$ & $11(64)$ & $0(0)$ & $16(62)$ & $10(45)$ & $N A^{c}$ \\
\hline Other hospital & $35(40)$ & $3(18)$ & $23(100)$ & $4(15)$ & $5(23)$ & $N A^{c}$ \\
\hline Emergency department & $8(9)$ & $3(18)$ & $0(0)$ & $4(15)$ & $1(5)$ & $N A^{c}$ \\
\hline Outpatient clinic & $7(8)$ & $0(0)$ & $0(0)$ & $1(4)$ & $6(27)$ & $N A^{c}$ \\
\hline Long-term institution & $1(1)$ & $0(0)$ & $0(0)$ & $1(4)$ & $0(0)$ & $N A^{c}$ \\
\hline Patients at home at least for one day, $n(\%)$ & $72(48)$ & $11(58)$ & $3(5)$ & $27(75)$ & $31(84)$ & $<0.001^{\mathrm{a}}$ \\
\hline Days spent at home, Mdn (range) & $0(0-28)$ & $8(0-28)$ & $0(0-16)$ & $21(0-28)$ & $24(0-28)$ & $0.001^{\mathrm{a}}$ \\
\hline Care days with community care service ${ }^{d}$, & $n=72$ & $n=11$ & $n=3$ & $n=27$ & $n=31$ & \\
\hline Mdn (range) & $1(0-28)$ & $0(0-24)$ & $1(0-5)$ & $5(0-28)$ & $0(0-28)$ & $0.001^{a}$ \\
\hline Hours of care by community care service ${ }^{d}$ & $n=36$ & $n=5$ & $n=2$ & $n=15$ & $n=14$ & \\
\hline Mdn (range) & $34(2-315)$ & $12(7-190)$ & $6(3-8)$ & $38(4-315)$ & $23(2-108)$ & $0.111^{\mathrm{a}}$ \\
\hline \multicolumn{7}{|l|}{ Type of community care service } \\
\hline Family education/support, $n(\%)$ & $35(97)$ & $5(100)$ & $2(100)$ & $14(93)$ & $14(100)$ & $N A^{c}$ \\
\hline Needs assessment, $n$ (\%) & $31(86)$ & $4(80)$ & $1(50)$ & $13(87)$ & $13(93)$ & $N A^{c}$ \\
\hline Monitoring of vital signs/general condition, $n(\%)$ & $29(81)$ & $5(100)$ & $2(100)$ & $13(87)$ & $9(64)$ & $N A^{c}$ \\
\hline Administration of medication, $n(\%)$ & $25(69)$ & $5(100)$ & $0(0)$ & $10(67)$ & $10(71)$ & $N A^{c}$ \\
\hline Interventions related to enteral feeds, $n(\%)$ & $22(61)$ & $5(100)$ & $1(50)$ & $13(87)$ & $3(21)$ & $N A^{c}$ \\
\hline Respiratory interventions, n (\%) & $18(50)$ & $2(40)$ & $0(0)$ & $11(73)$ & $5(36)$ & $N A^{c}$ \\
\hline Interventions related to excretion, $n(\%)$ & $14(39$ & $1(20)$ & $0(0)$ & $6(40)$ & $7(50)$ & $N A^{c}$ \\
\hline
\end{tabular}

NA Not applicable

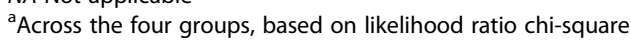

${ }^{\mathrm{b}}$ Representing the cumulative hospital admissions in all patients

'No significance testing conducted due to small numbers

${ }^{\mathrm{d} C o n s i s t i n g}$ of nurses, most of them specialised in paediatric and/or community nursing

2013, Feudtner et al. [13] showed however, that only $54 \%$ of hospital-based PPC programmes provided prenatal consultation [13].

Only half of the patients who spent time at home received community-based healthcare services. Recent data from Germany and the US show that the coordination and provision of specialised palliative home care can alleviate caregivers' distress and burden [27], and improve both the child's [28] and the caregivers' quality of life [27]. As reported by our study, community nursing care encompasses a range of service types. The high level of coordination with the leading team in the hospital and the expertise required makes it especially challenging. Subgroup analysis of our study's at-home population targeting facilitators for and barriers to EOL care in the home setting has been performed and is published elsewhere [29].

\section{Implications}

PPC is growing internationally and the provision of consultation by a hospital-based multiprofessional PPC team seems to be the favoured model of care [13]. There is some evidence suggesting that PPC programmes providing specialised services may reduce healthcare resource utilisation by reducing hospital admissions, shortening hospital stays, and lessening aggressive care to prolong life [30]. Additionally, provision of hospital-based specialised PPC may shift and extend the care setting beyond the hospital [30]. In order to provide good quality EOL care a high level of expertise with a good understanding of the different illness trajectories, and efficient collaboration across a variety of paediatric subspecialties is required. Outcome measurement has to be introduced into practice and prospective studies are needed to evaluate meaningful family-oriented clinical outcomes, quality of care, and the impact of specialised PPC to advance clinical practice and research in the field [30,31].

\section{Conclusions}

Swiss paediatric patients, similar to what is reported from other countries, experience high-intensity EOL care with invasive interventions, high medication counts 
and high symptom prevalence. Transitions between the inpatient and the home care setting were experienced by most patients outside the neonatology group. Professional home care was only utilised by half of the patients/families. The provision of specialised palliative and EOL care services, including the capacity of community healthcare services were limited. There is therefore a need for PPC services to be expanded to meet the specific needs of seriously ill children and their families in Switzerland.

\section{Abbreviations}

CCC: Complex chronic conditions; CPR: Cardiopulmonary resuscitation; DNR: Do not resuscitate; EOL: End-of-life; ICD: International Statistical Classification of Diseases and Related Health Problems; ICU: Intensive care unit; IQR: Interquartile range; PELICAN: Paediatric End-of-LIfe CAre Needs; PPC: Paediatric palliative care

\section{Acknowledgements}

We would like to thank Anouk Dorsaz, Marie-Madeleine Minder, Simone Keller, and Judith Wieland for their invaluable contribution in collecting the large amount of data. We also thank Heather Murray for her language editing. The authors wish to express their special thanks to all the members of the PELICAN Consortium who supported and facilitated the study conduction in all participating institutions: Marc Ansari; Christoph Aebi; Reta Baer; Maja Beck Popovic; Vera Bernet; Pierluigi Brazzola; Hans Ulrich Bucher; Regula Buder; Sandra Cagnazzo; Barbara Dinten; Anouk Dorsaz; Franz Elmer; Raquel Enriquez; Patricia Fahrni-Nater; Gabi Finkbeiner; Bernhard Frey; Urs Frey; Jeannette Greiner; Ralph-Ingo Hassink; Simone Keller; Oliver Kretschmar; Judith Kroell; Bernard Laubscher; Kurt Leibundgut; Reta Malaer; Andreas Meyer; Christoph Stuessi; Mathias Nelle; Thomas Neuhaus; Felix Niggli; Geneviève Perrenoud; Jean-Pierre Pfammatter; Barbara Plecko; Debora Rupf; Felix Sennhauser; Caroline Stade; Maja Steinlin; Lilian Stoffel; Karin Thomas; Christian Vonarburg; Rodo von Vigier; Bendicht Wagner; Judith Wieland; Birgit Wernz.

\section{Funding}

The research received funding from the following sponsors: The Swiss Cancer League / Swiss Cancer Research; Nursing Science Foundation, Basel, Switzerland; Federal Office of Public Health, Switzerland; Start Stipend Award, PhD Program in Health Sciences, Faculty of Medicine, University of Basel, Switzerland.

\section{Availability of data and materials}

The datasets generated and/or analysed during the current study are not publicly available due to ongoing subanalyses but are available from the corresponding author on reasonable request.

\section{Authors' contributions}

EC and EB designed the study. KZ elaborated the methodology, conducted the study, under the guidance of EC and EB, had full access to the data and performed the statistical analysis, and wrote the manuscript. KZ, KE and AS were involved in recruitment processes and data collection. All authors, including SE and NW, contributed to the interpretation of results, revised the manuscript critically and approved the final version.

\section{Ethics approval and consent to participate}

Human Research Ethics Committees from the 11 Swiss cantons in which the study took place approved the PELICAN study (leading committee: Kantonale Ethikkommission Zürich, KEK ZH Nr. 2012-0537). Parents of eligible deceased children were informed and invited to participate in the study by the former treating team, who also acted as gatekeeper as needed. Participation was entirely voluntary and written informed consent was obtained from all participants.

\section{Consent for publication}

Not applicable.

\section{Competing interests}

The authors declare that they have no competing interests.

\section{Publisher's Note}

Springer Nature remains neutral with regard to jurisdictional claims in published maps and institutional affiliations.

\section{Author details}

${ }^{1}$ Department Public Health (DPH), Nursing Science, University of Basel, Bernoullistrasse 28, 4056 Basel, Switzerland. 'Paediatric Palliative Care, University Children's Hospital Zurich, Children's Research Center CRC, Steinwiesstrasse 75, 8032 Zurich, Switzerland. 'Department of Pediatrics, Inselspital Bern University Hospital, Bern, Switzerland. ${ }^{4}$ Health Division, University of Applied Sciences Bern, Bern, Switzerland. ${ }^{5}$ School of Nursing, University of Pittsburgh, 3500 Victoria Street, Pittsburgh, PA 15261, USA. ${ }^{6}$ Institute of Higher Education and Research in Healthcare - IUFRS, University of Lausanne, Route de la Corniche 10, 1010 Lausanne, Switzerland. ${ }^{7}$ Nurse Research Consultant, Department of Woman-Mother-Child, Lausanne University Hospital CHUV, Lausanne, Switzerland. ${ }^{8}$ Paediatric Haematology-Oncology, University Children's Hospital UKBB, Spitalstrasse 33, 4056 Basel, Switzerland. 'Triemli Hospital Zurich, Zurich, Switzerland.

Received: 19 October 2016 Accepted: 29 January 2018

Published online: 16 February 2018

\section{References}

1. Ananth P, Melvin P, Feudtner C, Wolfe J, Berry JG. Hospital use in the last year of life for children with life-threatening complex chronic conditions. Pediatrics. 2015;136(5):938-46. https://doi.org/10.1542/peds.2015-0260.

2. Fraser LK, Miller M, Hain R, Norman P, Aldridge J, McKinney PA, Parslow RC. Rising national prevalence of life-limiting conditions in children in England. Pediatrics. 2012;129(4):e923-9. https://doi.org/10.1542/peds.2011-2846.

3. Feudtner C, Kang TI, Hexem KR, Friedrichsdorf SJ, Osenga K, Siden H, Friebert SE, Hays RM, Dussel V, Wolfe J. Pediatric palliative care patients: a prospective multicenter cohort study. Pediatrics. 2011;127(6):1094-101. https://doi.org/10.1542/peds.2010-3225.

4. Feudtner C, Christakis DA, Zimmerman FJ, Muldoon JH, Neff JM, Koepsell TD. Characteristics of deaths occurring in children's hospitals: implications for supportive care services. Pediatrics. 2002;109(5):887-93.

5. Hain R, Devins M, Hastings $R$, Noyes J. Paediatric palliative care: development and pilot study of a 'Directory' of life-limiting conditions. BMC Palliat Care. 2013;12(1):43. https://doi.org/10.1186/1472-684X-12-43.

6. Fontana MS, Farrell C, Gauvin F, Lacroix J, Janvier A. Modes of death in pediatrics: differences in the ethical approach in neonatal and pediatric patients. J Pediatr. 2013;162(6):1107-11. https://doi.org/10.1016/j.jpeds.2012.12.008.

7. Feudtner C, Feinstein JA, Satchell M, Zhao H, Kang TI. Shifting place of death among children with complex chronic conditions in the United States, 1989-2003. JAMA. 2007;297(24):2725-32. doi:297/24/2725 [pii]

8. Wolfe J, Orellana L, Ullrich C, Cook EF, Kang TI, Rosenberg A, Geyer R, Feudtner C, Dussel V. Symptoms and distress in children with advanced cancer: prospective patient-reported outcomes from the PediQUEST study. J Clin Oncol. 2015;33(17):1928-35. https://doi.org/10.1200/JCO.2014.59.1222.

9. WHO Definition of Palliative Care http://www.who.int/cancer/palliative/ definition/en/. 30.01.2016.

10. Wolfe J, Hinds PS, Sourkes BM. The language of pediatric palliative care. In: Wolfe J, Hinds PS, Sourkes BM, editors. Textbook of interdisciplinary pediatric palliative care. 1st ed. Philadelphia: Elsevier Saunders; 2011. p. 3-6.

11. Craig F, Abu-Saad Huijer H, Benini F, Kuttner L, Wood C, Feraris PC, Zernikow B. IMPaCCT: standards of paediatric palliative care. Schmerz. 2008; 22(4):401-8. https://doi.org/10.1007/s00482-008-0690-4.

12. Radbruch $L$, Payne S, EAPC Board of Directors. White paper on standards and norms for hospice and palliative care in Europe: part 2. Eur J Palliat Care. 2010;17(1):22-33.

13. Feudtner C, Womer J, Augustin R, Remke S, Wolfe J, Friebert S, Weissman D. Pediatric palliative care programs in children's hospitals: a cross-sectional national survey. Pediatrics. 2013;132(6):1063-70. https://doi.org/10.1542/peds.2013-1286.

14. Steele R, Siden H, Cadell S, Davies B, Andrews G, Feichtinger L, Singh M. Charting the territory: symptoms and functional assessment in children with progressive, non-curable conditions. Arch Dis Child. 2014;99(8):754-62. https://doi.org/10.1136/archdischild-2013-305246.

15. Morell E, Wolfe J, Scheurer M, Thiagarajan R, Morin C, Beke DM, Smoot L, Cheng $\mathrm{H}$, Gauvreau K, Blume ED. Patterns of care at end of life in children with advanced heart disease. Arch Pediatr Adolesc Med. 2012;166(8):745-8. https://doi.org/10.1001/archpediatrics.2011.1829. 
16. Wolfe J, Grier HE, Klar N, Levin SB, Ellenbogen JM, Salem-Schatz S, Emanuel EJ, Weeks JC. Symptoms and suffering at the end of life in children with cancer. N Engl J Med. 2000;342(5):326-33. https://doi.org/10.1056/ NEJM200002033420506.

17. Bergstraesser E, Zimmermann K, Eskola K, Luck P, Ramelet AS, Cignacco E. Paediatric end-of-life care needs in Switzerland: current practices, and perspectives from parents and professionals. A study protocol. J Adv Nurs. 2015;71(8):1940-7. https://doi.org/10.1111/jan.12650.

18. Zimmermann K, Bergstraesser E, Engberg S, Ramelet AS, Marfurt-Russenberger K, Von der Weid N, Grandjean C, Fahrni-Nater P, Cignacco E, Consortium P. When parents face the death of their child: a nationwide cross-sectional survey of parental perspectives on their child's end-of life care. BMC Palliat Care. 2016; 15(1):30. https://doi.org/10.1186/s12904-016-0098-3.

19. Gregory KE, Radovinsky L. Research strategies that result in optimal data collection from the patient medical record. Appl Nurs Res. 2012;25(2):10816. https://doi.org/10.1016/j.apnr.2010.02.004.

20. ICD-10 Online: 2016. http://apps.who.int/classifications/icd10/browse/2016/ en. Accessed 6 Nov 2015.

21. Blume ED, Balkin EM, Aiyagari R, Ziniel S, Beke DM, Thiagarajan R, Taylor L, Kulik T, Pituch $\mathrm{K}$, Wolfe J. Parental perspectives on suffering and quality of life at end-oflife in children with advanced heart disease: an exploratory study*. Pediatr Crit Care Med. 2014;15(4):336-42. https://doi.org/10.1097/PCC.0000000000000072.

22. UCLA: Statistical Consulting Group. Data analysis examples 24.01.2016.

23. Drake R, Frost J, Collins JJ. The symptoms of dying children. J Pain Symptom Manag. 2003;26(1):594-603.

24. Kassam A, Sutradhar R, Widger K, Rapoport A, Pole JD, Nelson K, Wolfe J, Earle CC, Gupta S. Predictors of and trends in high-intensity end-of-life care among children with cancer: a population-based study using health services data. J Clin Oncol. 2017;35(2):236-42. https://doi.org/10.1200/JCO.2016.68.8283.

25. Balaguer A, Martin-Ancel A, Ortigoza-Escobar D, Escribano J, Argemi J. The model of palliative care in the perinatal setting: a review of the literature. BMC Pediatr. 2012;12:25. https://doi.org/10.1186/1471-2431-12-25.

26. Wool C, Cote-Arsenault D, Perry Black B, Denney-Koelsch E, Kim S, Kavanaugh K. Provision of Services in Perinatal Palliative Care: a multicenter survey in the United States. J Palliat Med. 2016;19(3):279-85. https://doi.org/ 10.1089/jpm.2015.0266.

27. Groh G, Borasio GD, Nickolay C, Bender HU, von Luttichau I, Fuhrer M. Specialized pediatric palliative home care: a prospective evaluation. J Palliat Med. 2013;16(12):1588-94. https://doi.org/10.1089/jpm.2013.0129.

28. Friedrichsdorf SJ, Postier A, Dreyfus J, Osenga K, Sencer S, Wolfe J. Improved quality of life at end of life related to home-based palliative care in children with cancer. J Palliat Med. 2015;18(2):143-50. https://doi.org/10.1089/jpm.2014.0285.

29. Eskola K, Bergstraesser E, Zimmermann K, Cignacco E. Maintaining family life balance while facing a child's imminent death-a mixed methods study. J Adv Nurs. 2017;73(10):2462-72. https://doi.org/10.1111/jan.13304.

30. Conte T, Mitton C, Trenaman LM, Chavoshi N, Siden H. Effect of pediatric palliative care programs on health care resource utilization and costs among children with life-threatening conditions: a systematic review of comparative studies. CMAJ Open. 2015;3(1):E68-75. https://doi.org/10.9778/cmajo.20140044.

31. Bausewein C, Daveson BA, Currow DC, Downing J, Deliens L, Radbruch L, Defilippi K, Lopes Ferreira P, Costantini M, Harding R, et al. EAPC white paper on outcome measurement in palliative care: improving practice, attaining outcomes and delivering quality services - recommendations from the European Association for Palliative Care (EAPC) task force on outcome measurement. Palliat Med. 2016;30(1):6-22. https://doi.org/10.1177/ 0269216315589898.

\section{Submit your next manuscript to BioMed Central and we will help you at every step:}

- We accept pre-submission inquiries

- Our selector tool helps you to find the most relevant journal

- We provide round the clock customer support

- Convenient online submission

- Thorough peer review

- Inclusion in PubMed and all major indexing services

- Maximum visibility for your research

Submit your manuscript at www.biomedcentral.com/submit
Biomed Central 